13.1, followed by men's lacrosse at 6.80 and men's wrestling at 6.55. Seven-hundred-twenty-six injuries were reported by the ATCs of which the majority of injuries were to males $(77.5 \%)$ with injuries largely to the head/face, ankles, and knees. The leading type of injury across sports was ligament sprain (27.7\%), followed by concussion (23.2\%), and muscle strain (11.6\%). For all sports, boys had a significantly greater injury rate compared to girls and this was true across competitions and practices (Relative Risk $(\mathrm{RR})=2.79$, Confidence Interval $(\mathrm{CI}):=2.32-3.34$; $\mathrm{RR}=2.98, \mathrm{CI}:=2.28-3.88 ; \mathrm{RR}=2.88, \mathrm{CI}:=2.22-3.74$, respectively).

Conclusions The results of this research confirm the important role of various sports injuries among high school athletes with an emerging role for high school lacrosse. The results of these findings will be used to develop targeted interventions to reduce sports injuries in these athletes.

\section{THE EFFECTIVENESS OF INJURY PREVENTION PROGRAM ON REDUCING THE INCIDENCE OF LOWER LIMB INJURIES IN ADOLESCENT MALE SOCCER PLAYERS}

${ }^{1}$ Ahmed Fadhil Farhan ${ }^{2}$ Mohammed Jawad Kadhim, ${ }^{3}$ Ghadah Muayad Shihap. ${ }^{1}$ Department of Physiotherapy, Faculty of Health Sciences, Universiti Teknologi MARA, 42300 Puncak Alam Campus, Selangor, Malaysia; ${ }^{2}$ College of Physical Education and Sport Science, University of Baghdad, 47069 Baghdad, Iraq; ${ }^{3}$ College of Physical Education and Sport Science, University of Baghdad, 47069 Baghdad, Iraq

\subsection{6/injuryprev-2016-042156.972}

Background The highest incidence of injury is seen in adolescent playing pivoting sports such as soccer, basketball, and handball.

Objective: To examine the effectiveness of a neuromuscular prevention program in reducing knee and ankle injuries in adolescent male soccer players.

Methods Fifty Malaysian boys [25 experimental (EXP); or a 25 control (CON)] adolescent male soccer players (age $13.3 \pm 0.4$ yr; BMI $20.9 \pm 1.5 \mathrm{~kg} / \mathrm{m}^{2}$; stature: $160 \pm 0.1 \mathrm{~cm}$ ) from two sport schools, with $4.4 \pm 0.5$ years playing experience participated. The EXP group followed neuromuscular prevention program 5 days per week, for 12 weeks. The CON group was instructed to continue training and warm-up as usual. A neuromuscular exercise programme designed exclusively for adolescent soccer players was including jumping, eccentric strength, agility, balance, dynamic stretching and speed. Over 1 year all injuries were documented monthly by physiotherapist. Complete monthly injury reports were available for 50 players.

Results Eight lower limb injuries [Knee 3, (0.12 \pm 0.32$)$; Ankle $5,(0.19 \pm 0.38)]$ occurred in the EXP group, and 11 lower limb injuries [Knee 1, (0.03 \pm 0.12); Ankle 10, $(0.40 \pm 0.50)$ ] occurred in the CON group. The incidence of injuries per 1000 player- hours of training and playing soccer was 1.7 in the EXP group, and in the CON group 2.4 injuries per 1000 player-hours, which equates to $29 \%$ fewer injuries in the EXP group. Significance of difference between the EXP and CON groups was $\mathrm{p}<0.05$.

Conclusions Effective implementation of neuromuscular injury prevention program can reduce lower extremity injury incidence in adolescent male soccer players. Adolescent players need better education regarding injury prevention strategies and should include such interventions as part of their regular training.

\section{KNEE CONTROL AND JUMP-LANDING TECHNIQUE IN YOUNG BASKETBALL AND FLOORBALL PLAYERS}

${ }^{1}$ Mari Leppänen, ${ }^{1}$ Kati Pasanen, ${ }^{2,3}$ Juha-Pekka Kulmala, ${ }^{2}$ Urho M Kujala, ${ }^{4}$ Tron Krosshaug, ${ }^{5,6}$ Pekka Kannus, 7 Jarmo Perttunen, ${ }^{8}$ Tommi Vasankari, ${ }^{1} J a r i$ Parkkari. ${ }^{1}$ Tampere Research Centreof Sports Medicine, UKK Institute for Health Promotion Research, Tampere, Finland; ${ }^{2}$ University of Jyvaskyla, Finland; ${ }^{3}$ Agora Centre, University of Jyvaskyla, Finland; ${ }^{4}$ Oslo Sports Trauma Research Centre, Norwegian School of Sport Sciences, Oslo, Norway; ${ }^{5}$ Injury and Osteoporosis Research Centre, UKK Institute for Health Promotion Research, Tampere, Finland; ${ }^{6}$ Medical School, University of Tampere, and Department of Orthopaedicsand Trauma Surgery, Tampere University Hospital, Finland; ${ }^{7}$ Tampere University of Applied Sciences, Finland; ${ }^{8}$ UKK Institute for Health Promotion Research, Tampere, Finland

\subsection{6/injuryprev-2016-042156.973}

Background Poor knee alignment is associated with increased loading of the joints, ligaments and tendons, and may increase the risk of injury. The study purpose was to compare differences in knee kinematics between basketball and floorball players during a vertical drop jump (VDJ) task. We wanted to investigate whether basketball players, whose sport includes frequent jumplandings, exhibited better knee control compared with floorball players, whose sport involves less jumping.

Methods Players (aged 12-21 years) were recruited from six basketball and floorball clubs of the Tampere City district, Finland. Complete data was obtained from 173 basketball and 141 floorball players. Peak knee valgus and flexion angles during the VDJ were analysed by $3 \mathrm{D}$ motion analysis.

Results Larger knee valgus angles were observed among basketball players $\left(-3.2^{\circ}, 95 \% \mathrm{CI}:-4.5\right.$ to -2.0$)$ compared with floorball players $\left(-0.9^{\circ}, 95 \% \mathrm{CI}:-2.3\right.$ to 0.6$)(P=0.022)$. Basketball players landed with a decreased peak knee flexion angle (83.1응 $95 \%$ CI: 81.4 to 84.8 ) compared with floorball players (86.5으 $95 \% \mathrm{CI}$ : 84.6 to 88.4$)(P=0.016)$. There were no significant differences in height, weight or BMI between basketball and floorball players. The female athletes exhibited significantly $(\mathrm{P}<0.001)$ larger peak knee valgus angles $\left(-7.5^{\circ}\right.$, 95\% CI: -8.7 to -6.2$)$ than the male athletes $\left(3.4^{\circ}, 95 \% \mathrm{CI}: 2.1\right.$ to 4.6).

Conclusions This study revealed that proper knee control during jump-landing does not seem to develop in young athletes simply by playing the sport, despite the fact that jump-landings occur frequently in practice and games. Poor knee control was especially common among young female athletes. An important clinical implication of these findings is that young team sport athletes need to be taught a safer technique for landing and also need specific neuromuscular training in order to avoid potentially harmful movement patterns. (Int J Sports Med 2015, accepted for publication)

\section{MX SAFETY MOVEMENT AND SAFETY PROJECT}

Teija Piirto. Mx Safety Project Founder and Leader, Finland

\subsection{6/injuryprev-2016-042156.974}

Background MX Safety campaign started 2014. Campaign is lead by Teija Piirto who's mission is very personal due to a loss of her own brother. MX Safety's aim is to create encouraging safety debate and advance safety at off road tracks with track users. Target is zero fatal accidents in basic training environment and national and club level races, worldwide. All the work is done through voluntary work. Project has a wide range of knowledge 